\title{
PLANE CRASHING OVER BOSTON
}

You are thinking of something else the fuselage could crumple up like a piece of wrinkled fruit wrenched steel engines working against each other raaa, raaaa

the riveted wing-seam ripped open like a giant zipper falling you are falling the cockpit canopy blistered like a gourd before the captain's eyes the baggage compartment cracking suitcases banging together spilling silly women's hats hairbrushes bottles of shaving lotion sailing through the sky 20,000 feet down breaking like eggs against rocks a woman's slip dangling by one strap from a treebranch like a deflated parachute like satin slipcovers like the loosed pages of a magazine fluttering slowly to the ground like leaves a red-haired stewardess trips and falls against you as the plane veers there is an instant of pleasure a bundle of fragrant hair passes along your cheek one breast beneath a sheer white blouse brushes your shoulder and then the 
deadly impact the

collapsing vertebrae the neck snapped loose at the medulla oblongata the windows exploded the mouthful of debris and the siren-like whistling of the black winds of chaos

ONE READER WRITES:

She would see it in Time Magazine: a picture, himself in the foreground, still strapped to the seat, bent double across the belt, chin on chest, elbows limp, hands drooping and swollen, one shoeless foot two in ches deep in muck, slightly deformed at the ankle, collar and cuffs amazingly spotless, a bolt from the tail-fin blown like a needle through his liver, blood and yellow bile oozing out through the stain on his suit, slowly filling the chromium ashtray in the armrest, cigarette butts rising to the top, overflowing; rust already setting in, melted plastic, pieces of burnt cloth, the ruined spirals of aluminum girders, lymph and ectoplasm flowing green in the mudpuddles folded unused vomit bags stirring in the wind. 